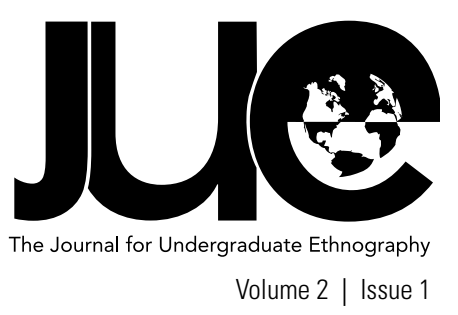

\title{
Opening Doors and Sitting on Floors: Public Events in Private Spaces: the (re)-appropriation of space through grassroots events in Halifax
}

\section{Samantha Levy and Susannah Church}

Dalhousie University, Halifax Nova Scotia Canada,

samantha.k.levy@gmail.com \& susannah.church@gmail.com

\section{ABSTRACT}

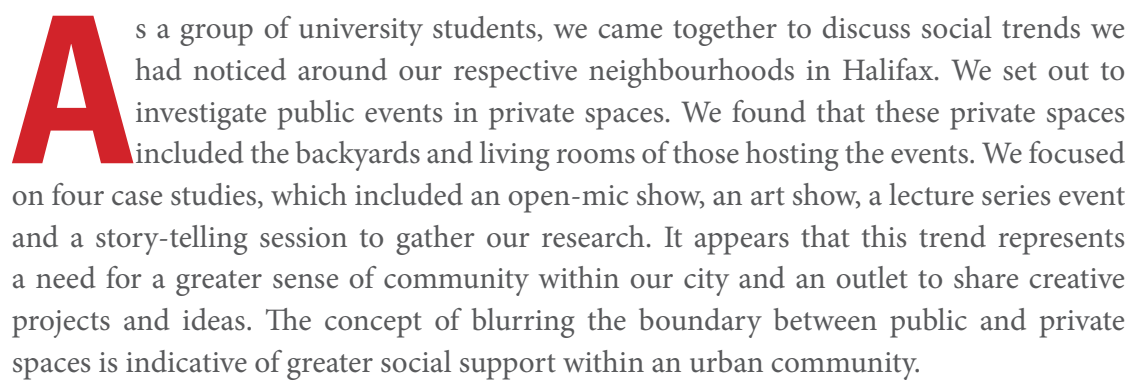

Keywords: community, urban, social, public 


\section{We behave differently in someone's living room or backyard than we would in a lecture hall or cafe, so a reading series run out of the home on Allan St. would have a very different 'feel' than one in a bookstore on Spring Garden Road, and a backyard lecture series would demand different social cues than one held at a university.}

${ }^{1}$ In this article, I have changed the names of people I mention in order to protect their confidentiality.

\section{INTRODUCTION:}

We have noticed a recent trend in the city of Halifax, Nova Scotia, of public events being held in traditionally private spaces, namely in peoples' homes. Does this phenomenon have something to do with the lack of public spaces available for these types of ventures, or is this development a sign of a wider cultural shift? Does it reflect a common desire for a greater sense of trust and community within the city, or could this be merely an aesthetic preference? Our project aims to explore these questions and to look broadly at the reasons why so many of these events were created, and what people's reaction has been to them. We are interested in whether or not these events create community where it is otherwise lacking or, conversely, if they are signals of a healthy, active community. Our research aims to find the motivations behind public events in private spaces, and to determine how these events reflect and satisfy the needs of an urban community. We will be exploring this question through four case studies: The Monday Night Agricola Street Open Mic is a weekly drop-in openmic night held in a residential living room; The Allan Street Reading Series is a monthly salon that is open to the public with a curated selection of presenters hosted in a residential living room; The Fuller Terrace Lecture Series is a bi-weekly, theme-based lecture series that solicits lecturers through open-calls presented in a residential backyard/alleyway; Ben and Zoe's Art Gallery is a sporadic popup gallery hosted in a residential home, showcasing the art of their friends and peers but open to public perusal and purchase. 


\section{RESEARCH FRAMEWORK}

Since our research question is primarily concerned with examining the notion of community and the appropriation of public and private spaces, we will proceed to examine how these terms are defined and how the events that we've researched may challenge these definitions. It is difficult to reach a consensus about the meaning of community, because the term means different things to different people. Laura Pappano writes that it is easy to apply the notion of community "to a range of experiences... community [brings] different people together in common pursuit across lines of difference...we understand a need for each other, and - perhaps most critically - we know that our destinies are bound up with one another" (Pappano, 2001, 185). Wellman and Leighton describe community as a network of interpersonal ties that provide sociability to members of a common locality with shared sentiments and activities (Wellman, 1979, 365). They note that the inclusion of locality in this definition has caused some to conflate community and neighbourhood; for our research, it proved significant that these events were all located in Halifax's North End, a neighbourhood known for its social involvement. Pappano notes that while most people acknowledge the importance of community in fostering identity and creating connections, they are increasingly likely to retreat to the private realm; she writes "why open the door when it is challenging enough to manage our own lives?" (Pappano, 2001, 208). As we will show, the events we studied seem to defy this tendency by opening their doors to bring the public into private spaces.

In Public and Private Spaces of the City, Ali Madanipour describes the three types of places that exist within the city: intimate, interpersonal, and impersonal; the home would exemplify the intimate, the interpersonal space would include schools, workplaces, community centres, and so on., and city streets and places of public use would be categorized as impersonal (Madanipour, 2003, 1). According to Madanipour, "ever since the rise of the city...public- private distinction has been a key organizing principle, shaping physical space of cities and the social life of their citizens" (1). How one delineates the public and private realms is important because whether or not we view something as 'private' or 'public' influences our relation to the space, our relationships in the space, and importantly our desire or ability to even use the space. We behave differently in someone's living room or backyard than we would in a lecture hall or cafe, so a reading series run out of the home on Allan St. would have a very different 'feel' than one in a bookstore on Spring Garden Road, and a backyard lecture series would demand different social cues than one held at a university.

For many Westerners, the home epitomizes the private sphere, yet this was not always the case; though we may currently consider the home to be the materialization of the private, in the Middle Ages "there were no boundaries between professional and private life. Working and living were combined in the typical bourgeois townhouse of the fourteenth century...life was, indeed, 'lived in public'...the notions of privacy, function and comfort as understood today did not exist" (Madanipour 2003, 68). However, starting in Victorian England and continuing into the modern era, "the public character of the house was lost and some of its functions were taken up by the club, the cafe [in France] and the public house [in Britain]" (72). The strict separation of public and private in social interactions of the time was reflected in the home, and integrated social bonds gave way to commodified social relations wherein private, domestic space needed to be differentiated from public, social space (75). So, the home became synonymous with the "intimate", and public spaces, such as the aforementioned bars and cafes, became places where people could engage in interpersonal relationships. It is important to note that the sociocentric modes of pre-Victorian interaction still prevail in many parts of the world, meaning that this obsession with privacy is more prevalent in Western society, while society-centric life is still the norm throughout many other cultures. In truth, this absolute demarcation or differentiation between private and public is really a product of modern, western societal values.

In contrast to the intimacy of private spaces, the public sphere is typically characterised by interpersonal and impersonal relations and interactions with others who impact your life but with whom you do not have an intimate relationship. Since the public sphere requires you to handle relationships that are both impersonal and interpersonal, the public is constructed and communicated through conduct and performance in a much more defined manner than is the private. In effect, public spaces are socially constructed through the "phenomenological and symbolic experience of space as mediated by social processes such as exchange, conflict, and control" (Low, 1996, 861); these processes are also encountered in the private sphere, however the dual levels in which they must be navigated--the impersonal, the interpersonal, and sometimes even the personal--in public makes them especially pertinent to its characterisation. Through social exchanges and use of space, a public space may be socially constructed in a venue that is typically private; symbolic meaning 
of a space does not depend on physical characteristics, so while a bunch of couches and a TV may imply living room, the scenes and actions of an open-mic every Monday night suggests otherwise.

Above all, most definitions of public space emphasize "the necessity of access, which can include access to a place as well as to the activities within it" (Madanipour, 2003, 111). The idea of access is crucial, because it can help us explain how domestic spaces such as living rooms and backyards can be transformed into public spaces once open access is granted. According to Madanipour, "one way to confront the range of ambiguities and overlaps is to see that the definition of the 'public' may depend on its context and...it seems that depending on what we define as private sphere, the public sphere is defined in relation to it" (113). Put another way, when the private is personal, or intimate, then the public must satisfy the impersonal and interpersonal functions. However, when the private becomes an interpersonal space, as it does when events such as readings, lectures, musical performances, and art shows get brought into the home, the differences between them are notably blurred and, as a consequence, the city is in some small way transformed.

The shape of a city and of urban life are characterized by the way in which the public/private distinction is made; as Madanipour writes: "a central challenge in urbanism is to find a balance between the public and private realms" (241). The balance is seriously challenged by the emergence of open, seemingly public spaces in the traditionally private domain, and most of the time this ambiguity proves to be quite confusing, as an experiment in other cities seems to show. Alex and Sebastian Cowan ran an art and performance venue, Lab Synthèse, out of their loft apartment in Montreal, and though for them the space was an intimate one in which they opened their door for the occasional interpersonal interaction, attendees had a hard time differentiating between an open-private space and the traditional public space. Though the Cowans lived and worked at Lab Synthèse, to others it was just a party venue: “There's a certain degree of respect when you enter someone's home that you don't enact in a public space...the overlap between public and private made living at Lab feel a lot like work" (Coleman, 2010, 12-13). It was because their venue took on an increasingly "public" feel - with people showing up uninvited, people showing up who were outside their social circle, people not respecting their space - which they eventually shut the Lab down (13).
It is clear from the literature that our four case studies represent a unique approach to the creation of urban community through the blurring of traditional public/private distinctions. Further discussions of these events in our research findings support this claim. These events contest 'the merciless separation of space' that Georg Simmel said to be a defining aspect of city-living (Coleman, 2010, 11) and they work to engage the community by radically redefining social barriers associated with space and place.

\section{RESEARCH DESIGN AND METHODS}

To sum up so far, our research investigates why the creation of these "public events in private spaces" occurred in Halifax and how people's social relations are negotiated in these events. While most studies examine the privatization of public space in the negative sense of commoditisation, we will explore the ways in which the blurring of public and private has been employed in order to extend public usage and create more communal spaces. By looking at the social construction of their spaces, we look to see if these events were created out of a perceived need for more intimate relations in the city, in light of the levels of social isolation that people experience in their daily lives in Halifax. We expect to find that these events have arisen out of a need for intimate and private space, and that they arise in the city because of the impersonal, compartmentalized elements of society where there is a clear division between 'public' and 'private' life. We posit that these events successfully blur the lines between 'public' and 'private' and give participants a greater sense of community and connection in their lives.

To address our research question we primarily used the method of semi-structured interviews, both short 'vox pop' and longer interviews, to collect our data. We conducted eighteen 'vox pop' interviews with attendees of these events, and four longer interviews with hosts. The term 'vox pop' refers to the short, informal style of interview commonly used in news programs as a way of polling pedestrians. Interviewing was the most appropriate method because we were interested in the motivations, perspectives, and impressions that the attendees and hosts had in relation to these events. We asked such questions as: Why were these events needed? Did people feel isolated in their Halifax urban life? What was the atmosphere of these events and how did they differ from more conventional 
spaces? Allowing participants to answer in their own words gave us, as researchers, the most lucid picture of their experiences.

We also searched for newspaper articles about the events in the local press. This allowed us to draw on the point of view of a person who was not attending the event because of perceived inaccessibility; it gave us access to perspectives of those who were not connected to the events, thus placing them in a larger social context.

We obtained our data by contacting hosts of the events through their publicity material and arranging interview times that worked for both parties. We interviewed five hosts for three of the events; we were unable to get an interview with the founder of the reading series because of scheduling conflicts. The interviews ranged in time from thirty minutes to two hours, the latter being the interviews with Ben Caplan and Julia Feltham, which were recorded on videotape for presentation purposes. In order to speak to attendees, we either attended the event or located them through contacts we had or who were recommended by the host. The only events that we were able to attend to collect research during the writing process were the Open Mic and the Reading Series; however, the other two events had also been attended by the authors prior to their beginning this research project. Most of the hosts and attendees were accessible and happy to talk openly and personally about these events, which may be a result of the intimate nature of these events. We then analysed the data by gathering our interview responses together, along with comments found in the newspaper, and compared and contrasted the findings. We looked for particular themes and insights that were relevant to our research question.

Our research ethics were grounded upon the informed consent of the individuals to be interviewed. We did not elicit information revealing private, or potentially divisive or controversial subjects that would cause ethical concern about the impact of our research. All attendees remained anonymous in our findings and all the hosts gave us consent to use their names and pictures.

\section{FINDINGS}

Artistic events such as the ones studied are meant to engage the community; bringing these events into the home reveals a further desire for intimacy and interaction within a sometimes hostile and anonymous urban setting. These events create a sense of urban community that Fran Tonkiss describes as "villages in the city, based on familiarity and shared cultural norms" (2005, 9). Tonkiss notes how rural incomers usually import these intimate forms of community, and indeed our event organizers all come from small cities or rural towns.

All five hosts that were interviewed had grown up in relatively small cities or towns (predominantly from the Atlantic provinces of Canada, namely, Nova Scotia, New Brunswick, Prince Edward Island and Newfoundland). Not one of the hosts was from a large city, or even a city the size of Halifax (population 373,000 in 2006), and our interviews confirmed that there was definitely a pattern of recreating the sense of community the hosts had felt growing up. Julia Feltham, cohost of the Open Mic, mentioned, "being raised by a pile of Newfoundlanders, I remember as a little kid going to little towns and you called everybody uncle and aunt and I literally thought I was related to the entire island. I have been raised to believe that everyone is my family." The 'family community' Julia was raised by has shaped the way she treats the audience at the Open Mic. Treating everyone like a brother or sister is not the norm in an urban environment, so public events in private spaces begin to dissolve our concept of the stranger. The desire for a connection and resistance to social isolation proved to be important motivators for our hosts in creating these events. While a sense of community is clearly a huge motivator, we must not ignore the significance of bringing this community into their homes. We asked Julia how public the event actually is, given that she seems to recognize most faces, to which she responded, "it is really public. Often people will think I know someone 'cause I hug them when they come in the door, but still - it doesn't mean that I know them." She strongly believes that "the fact that we have our doors open make us more safe."

Ella Tetrault, one of two hosts for the Fuller Terrace Lecture Series, told us that one of the main goals for her event "was to come to know their community differently and expand that community and their understanding with each other". This goal was also in conjunction with an interest in the activity of public speaking and shared knowledge. When asked if she found that having the event in her backyard deterred people from coming she responded that "having the event in our backyard may turn people off, but I do not believe a university lecture hall is 
any more accessible. Every space can be intimidating, but the backyard has the potential to be unintimidating because it is so informal. Every space has its limitations."

The motivation behind creating events such as these definitely speaks to the issue of social isolation and urban alienation. Ben Caplan, the other Open Mic host explained:

"it is very easy to become isolated in modernity, you've got your job and you're a cog in the machine, you're supposed to rotate in a particular place, where do you go to meet people? What if you don't want to go to a bar and drink? What if you're not going to classes anymore? And your friends moved away. To be able to connect with people of a like mind and have those kinds of enriching relationships, a lot of people really cherish having access to this kind of stuff and to be part of a community."

Ella Tetrault agreed with this sentiment, explaining that the lecture series was an attempt to take the somewhat superficial interactions one would have at a party and translate them into more meaningful, shared experiences. Another trend among the hosts was that they were all recent graduates, in their mid to late 20's. We interpret a correlation between the loss of a schoolbased community and the creation of an interest-based support system. Specifically, the desire to connect through the exchange of ideas, stories, and mutual interests is very reminiscent of the university environments from which the hosts had recently graduated.

Based on our participant observation at the events, it was very clear that the audiences are predominantly students, or recent university graduates. This pattern demonstrates the possible exclusiveness of the events; although they claim to be public, it is important to understand who feels welcome and why. In an interview with Halifax News, North End resident Mark Butler expressed this same sentiment about the Fuller Terrace Lecture Series: "A lot of people seem to know each other here, but it would be really interesting too if you could bring together neighbours who don't usually talk and have different lives, ages and professions" (Burnet and Schurman, 2010). This apprehension about going to a public event in a private space was reiterated by one of the attendees at the Reading Series. Though she went on to read one of her works at the event, she was initially reluctant to attend, telling us that: "I'd heard of the reading series and been interested in attending but without an expressed invitation or a friend-of-a-friend relationship, I wouldn't have been comfortable." After having participated as a first time reader she expressed gratitude "to have been able to start out at the reading series because the atmosphere was so friendly and open".

Most of the attendees interviewed for each event said that they knew someone related to the event, whether it is one of the hosts or someone participating in the event as an artist or performer. This is also an indicator of exclusivity - people are much more likely to attend if they feel welcome, whether or not they were invited. Many attendees seemed to have found out about the event through word of mouth. It seems that running into a friend on the street and being told about the event in passing is a common way to be invited. For example, one writer who presented at the reading series confessed that she was invited to read after a chance encounter with the host at a bar. Although each event has had other mediums of publicity, such as write-ups in local weekly newspaper The Coast and The Dalhousie Gazette, and even interviews on the local programs on CBC Radio, verbal invitation seems to be most effective in influencing attendance. This has been one of the reasons that growth outside of specific social circles has been slow, because without the time and resources that a bar or a bookstore would have for publicizing their events, most have had only limited success reaching audiences outside their social circles. However, this informal process is also an important part of the alternative culture of these events; during her interview with Ella Tetrault, one of the researchers was even invited to give a lecture next summer.

When asked if they enjoyed events in private spaces more than events in more conventional spaces, all attendees responded 'yes'. Attendees used words such as 'inviting, 'grassroots', 'intimate, 'magical', 'comfortable', 'feeling of home' to describe the atmosphere of the private space-based events. Most attendees recognized between 5 and 10 other people at the event, usually a couple of the people they knew before ever coming to the event and the others they either recognize from similar types of events or from just having seen them around Halifax. 
There were definitely limitations that we experienced throughout this research process. Besides the obvious time limit (research was conducted for a one-term class), the main limitation was that it was difficult to obtain information about people who had heard of but chose not to attend the events we studied. It would have also been very interesting to compare our findings by speaking with people who organize or attend similar events in more conventional public spaces.

\section{CONCLUSION}

With regards to our research question, we successfully discovered the hosts' motivations for creating and maintaining their events. We have also concluded that the overall response from their audiences was positive and has encouraged them to keep the events public. We have learned that the events were created as a response to a strong sense of community, rather than a lack thereof, though it is important to note that these events do not cater exclusively to the issue of social isolation common within urban settings. Rather, the intention for bringing these public events into private spaces was to bring people together around a social need by providing artistic outlets. The desire for a connection and resistance to social isolation proved to be important motivators for our hosts in creating these events. While a sense of community is clearly a huge motivator, we must not ignore the significance of bringing this community into the private home. Events such as the ones studied are meant to engage the community bringing these events into the home reveals a further desire for intimacy and interaction within a sometimes hostile and anonymous urban setting. These events create a sense of urban community that Fran Tonkiss describes as "villages in the city, based on familiarity and shared cultural norms" (Tonkiss, 2005, 9). Tonkiss notes how rural incomers usually transport these intimate forms of community, and indeed our event organizers all come from small cities or rural towns.

Overall our methods of long and short interviews were suitable for obtaining the information, due to the limited sample size, the scope of our research was quite limited. Nevertheless, interviews were a suitable form of research in the sense that they required personal participation in events that were founded upon the principles of exchange and social interaction. Furthermore, the semi-structured nature of the interviews allowed hosts and attendees to express themselves without being confined to predetermined survey answers. Based on our interviews and our literature review, we concluded that these events redefined and socially constructed the spaces in which they were held, blurring the participants' conceptions of public and private, and thus influencing their interactions with one another. Due to their unique settings and DIY-styled initiative, the hosts have effectively re-defined the public/private distinction, creating spaces capable of fostering a new type of community in the city. 


\section{WORKS CITED}

Burnet, Mary \& Schurman, Georgia (2010, August 15). Growing Backyard Lecture Series Provides Space for Showing and Telling. Halifax News

Coleman, Madeline. (2010). How to Run a DIY Party Space (without the cops shutting you down). Maisonneuve Magazine, 37

Low, Setha. (1996). Spatializing Culture: The social production and social construction of public space in Costa Rica. American Ethnologist, 23(4): 861-79

Madanipour, Ali. (2003). Public and Private Spaces of the City. New York: Routledge

Pappano, Laura. (2001). The Connection Gap: Why Americans feel so alone. New Jersey: Rutgers University Press

Tonkiss, Fran. (2005). Space, the City and Social Theory: Social relations and urban forms. Cambridge: Polity Press

Wellman, Barry, \& Leighton, Barry. (1979). Networks, Neighborhoods, and Communities: Approaches to the Study of the Community Question. Urban Affairs Quarterly, 14 (3): $368-90$

This work is licensed under a Creative Commons AttributionNonCommercialNoDerivs 3.0 Unported License. 